\title{
Efficacy and Safety of Anal Encirclement Combining the Leeds-Keio Artificial Ligament With Injection Sclerotherapy Using Aluminum Potassium Sulfate and Tannic Acid in the Management of Rectal Prolapse: A Single-Center Observational Study
}

\author{
Tatsuya Abe, Masao Kunimoto, Yoshikazu Hachiro, Kei Ohara, Mitsuhiro Inagaki \\ Department of Proctology, Kunimoto Hospital, Asahikawa, Japan
}

Purpose: Perineal procedures are an important surgical option for frail and high-risk patients with rectal prolapse. This study aimed to evaluate the efficacy and safety of combined therapy using injection sclerotherapy, with aluminum potassium sulfate and tannic acid (ALTA), and the Thiersch procedure, using the Leeds-Keio ligament (ALTA-Thiersch).

Methods: This study included 106 consecutive patients (mean age, 81.2 years) who underwent ALTA-Thiersch for rectal prolapse. The procedure was performed under caudal epidural anesthesia. ALTA was injected into the submucosa from the tip of the prolapsed rectum down to the dentate line, circumferentially, at 20 to 40 locations. The ligament tape was placed outside the external sphincter muscle and at an approximate depth of $2 \mathrm{~cm}$ into the middle anal canal.

Results: Of 106 patients, rectal prolapse was cured shortly after surgery in 105 patients. An additional tape was inserted in 1 patient who had persistent prolapse. Postoperative complications were observed in 27 patients (25.5\%). Fecal impaction occurred in 12 patients; however, since it was temporary, no tape removal was required. Of the 12 cases in which the tape was infected or exposed, 11 required tape removal. There were 18 cases of recurrence at a mean follow-up of 22.1 months. Cumulative recurrence rates at 3 and 5 years were $21.3 \%$ and $38.6 \%$, respectively.

Conclusion: ALTA-Thiersch is a simple and safe procedure for rectal prolapse, having reasonable outcomes. The use of the Leeds-Keio ligament for anal encircling can help compensate for the disadvantages of the Thiersch operation.

Keywords: Rectal prolapse, Sclerotherapy, Fecal impaction, Surgical wound infection, Aluminum potassium sulfate and tannic acid

\section{INTRODUCTION}

Rectal prolapse is a disorder characterized by a full-thickness intussusception of the rectal wall that extrudes through the anus.

Received: Aug 11, 2021 Revised: Sep 18, 2021 - Accepted: Sep 23, 2021 Correspondence to: Tatsuya Abe, M.D., Ph.D.

Department of Proctology, Kunimoto Hospital, 5-chome, 4 Jodori,

Asahikawa 070-0034, Japan

Tel.: +81-166-25-2241, Fax: +81-166-23-1726, E-mail: kunimoto@hokkai.or.jp ORCID: https://orcid.org/0000-0002-7215-3597

(C) 2021 The Korean Society of Coloproctology

This is an open-access article distributed under the terms of the Creative Commons Attribution NonCommercial License (https://creativecommons.org/licenses/by-nc/4.0) which permits unrestricted noncommercial use, distribution, and reproduction in any medium, provided the original work is properly cited.
Some of the symptoms associated with this condition, such as anal pain, bleeding, constipation, and fecal incontinence, may be relieved by medication; however, rectal prolapse cannot be corrected nonoperatively [1].

While numerous operative procedures for rectal prolapse have been described in the literature, only a few procedures are routinely advocated. Generally, these procedures employ 1 of 2 main approaches, abdominal or perineal, usually determined by the patient's age, defecation function, and comorbidities, along with the surgeon's preference or experience [2]. In patients with an acceptable level of risk, the procedure of choice should typically incorporate transabdominal rectal fixation. On the other hand, the perineal approach is minimally invasive but has a relatively higher recurrence rate, making it suitable for frail, elderly, or high-risk 
patients [1].

Injection sclerotherapy and the Thiersch procedure (anal encirclement) are the most minimally invasive perineal procedures for treating rectal prolapse. In 2014, we devised a new treatment method that combines injection sclerotherapy using aluminum potassium sulfate and tannic acid (ALTA) with the Thiersch procedure, using a new expandable tape. The results of the combination procedure (ALTA-Thiersch) showed a positive outcome in patients with rectal prolapse [3]. The ALTA solution, an injectable sclerosant based on Xiaozhiling, which was developed in China in the 1970s [4], has been used to treat hemorrhoids in Japan since 2005 [5]. ALTA sclerotherapy proved to be highly effective, even for grade 3 to 4 hemorrhoids, and its effects were comparable with those of hemorrhoidectomy [5, 6]. ALTA is not currently approved by the U.S. Food and Drug Administration; however, it is approved for medical use in major Asian countries, including South Korea, and is also used for the treatment of rectal prolapse and rectocele $[3,7,8]$.

In 1891, Thiersch [9] first described a simple method for the treatment of rectal prolapse in which the anus was encircled with a silver wire. Despite the initially encouraging results of this easy and low-cost procedure, it did not gain popularity because of the high recurrence rate associated with it. The most common reason for recurrence of rectal prolapse is removal of the encircling material due to infection, tissue erosion, or fecal impaction. Nylon threads, silastic sheets, Teflon tape, and polyethylene mesh are currently used to reduce the risk of these complications, but they are still rigid, and fecal impaction or tissue erosion may persist because of the non-expandability of these materials [10-13].

The Leeds-Keio ligaments, originally developed for knee ligament reconstruction, were adopted for clinical use in 1982. The artificial ligament has a mesh structure woven with polyester fibers and sufficient tensile strength for anterior cruciate ligament reconstruction. In addition, fatigue tests have shown satisfactory durability, and functional stability of the knee joint has been reported on long-term use of the Leeds-Keio ligaments [14].

In 2005, Iwadare et al. [15] modified the Leeds-Keio ligament for use in the Thiersch procedure. The following modifications were made: (1) expandability was increased (up to 2 times the original) to avoid fecal impaction and tissue erosion; (2) threads were attached to help tie both ends of the tape; and (3) the artificial ligaments were covered in vinyl film to prevent contamination during tape insertion. They performed the Thiersch procedure with the modified ligament tape in 26 patients with rectal prolapse and reported a recurrence rate of $11.5 \%$ with no case requiring tape removal [15]. In a previous study, we performed the ALTA-Thiersch procedure using the same tape in 23 patients with rectal prolapse, with a recurrence rate of $13.0 \%$ and no tape removal required [3].

Over time, as we performed more ALTA-Thiersch procedures, we observed that there was an increased incidence of case of tape removal due to infection or tape exposure. Therefore, we wanted to reconfirm the outcomes of the ALTA-Thiersch procedure in the management of rectal prolapse. The present observational study was designed with the primary aim of assessing the clinical efficacy of ALTA-Thiersch in patients with rectal prolapse. The secondary aim was to evaluate the safety of the procedure by monitoring the complications and requirement for tape removal.

\section{METHODS}

This study included consecutive patients who visited Kunimoto Hospital and underwent ALTA-Thiersch for rectal prolapse between January 2009 and December 2020. The inclusion criteria for ALTA-Thiersch at our hospital were a full-thickness rectal prolapse with a patulous anus (approximately $\geq 35 \mathrm{~mm}$ in diameter), and high risk for an abdominal procedure because of frailty, advanced age, or significant comorbidities. The inclusion criteria and surgical technique for ALTA-Thiersch were not changed during the study period. This study was approved by the Institutional Review Board of Kunimoto Hospital (No. K09-003), and written informed consent was obtained from all the patients. Preoperative assessment included a questionnaire regarding bowel movement, medical history, and comorbidities, along with digital rectal examination and anoscopy, and if possible, sigmoidoscopy and barium defecography.

\section{Surgical technique}

Preoperative preparation consisted of 2 sodium bicarbonate suppositories administered just before the surgery. No major bowel preparation was necessary. ALTA-Thiersch was administered in the operating room under caudal epidural anesthesia with the patients in the jackknife position. Local anesthesia was administered to patients taking anticoagulants to prevent spinal epidural hematomas.

First, the rectum was prolapsed to the maximum extent using forceps (Fig. 1A). Using a proctoscope, a 25-gauge injection needle mounted on a $5-\mathrm{mL}$ syringe was used to evenly inject the ALTA solution (0.5-1.0 mL; Zione, J-Dolph Pharmaceutical Co., Ltd., Osaka, Japan) into the submucosa from the tip of the prolapsed rectum down to the dentate line, circumferentially, at 20 to 40 locations (Fig. 1B). The tissues where the ALTA solution was injected were gently kneaded to promote even distribution.

Subsequently, the operative field was redraped for the Thiersch procedure. Two $1-\mathrm{cm}$ incisions were made anteriorly and posteriorly, $3 \mathrm{~cm}$ away from the anal verge. For females with a narrow perineum, the anterior incision was taken as far away from the anus as possible. The incisions were deepened by $2 \mathrm{~cm}$ using blunt dissection, and a tunnel was created through the ischiorectal space on one side of the anal canal using Kelly forceps. Where the forceps reached the incision on the opposite side, the surgeon grasped 1 thread of a Leeds-Keio ligament for Thiersch use (LK5T-130, Yufu Itonaga Co., Ltd., Tokyo, Japan) (Fig. 2) and pulled it through the tunnel. The process was repeated on the other side, 

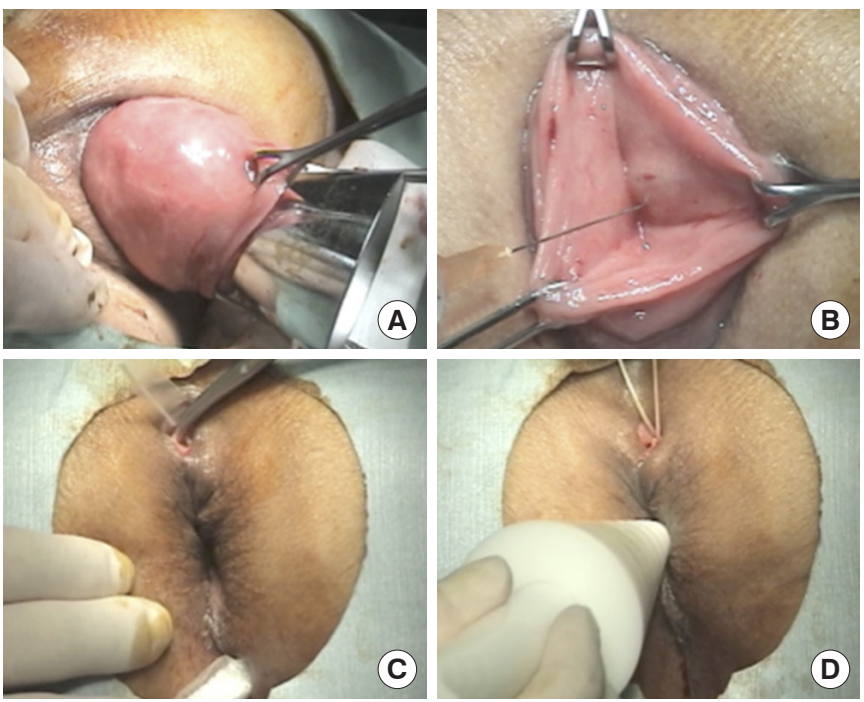

Fig. 1. Aluminum potassium sulfate and tannic acid (ALTA)Thiersch procedure. (A) The rectum was prolapsed to its maximum extent using forceps. (B) The ALTA solution was injected using a 25-gauge injection needle. (C) The artificial ligament tape was routed around the anal canal. (D) Both ends of the tape were tied together with attached threads.

and the ligament tape was routed around the anal canal (Fig. 1C). The tape was placed outside the external sphincter muscle and at an approximate depth of $2 \mathrm{~cm}$ into the middle anal canal. Both ends of the tape were tied together with the attached threads. In Fig. 1D, the proper diameter is measured with a caliper ruler, but empirically, ligation at the base of the attached thread leads to an optimal anal diameter $(20-25 \mathrm{~mm})$. The 2 incisions were sutured using 4-0 Vicryl (Ethicon Inc., Raritan, NJ, USA).

Postoperatively, the patients were administered prophylactic oral antibiotics (cefaclor, $750 \mathrm{mg} /$ day) for 3 days with no dietary restrictions. The patients were hospitalized for 1 week because of the possible difficulties in defecation for several days after the operation.

\section{Outcome measures}

Follow-up office visits were recommended for all patients at 2 weeks, and subsequently at 1,3 , and 6 months, and 1,2 , and 3 years after surgery. Subsequent follow-ups were voluntary. The follow-up comprised digital rectal examination, anoscopy, and collection of patient-reported outcomes regarding defecation and prolapse. Early (occurring within 1 month postoperatively) and late (occurring after 1 month) postoperative complications were analyzed. In this study, full-thickness prolapse recurrence was defined as recurrence. All data were retrospectively collected from the medical records of the participants. The outcome measures were postoperative complications, tape removal rates, and recurrence rates.

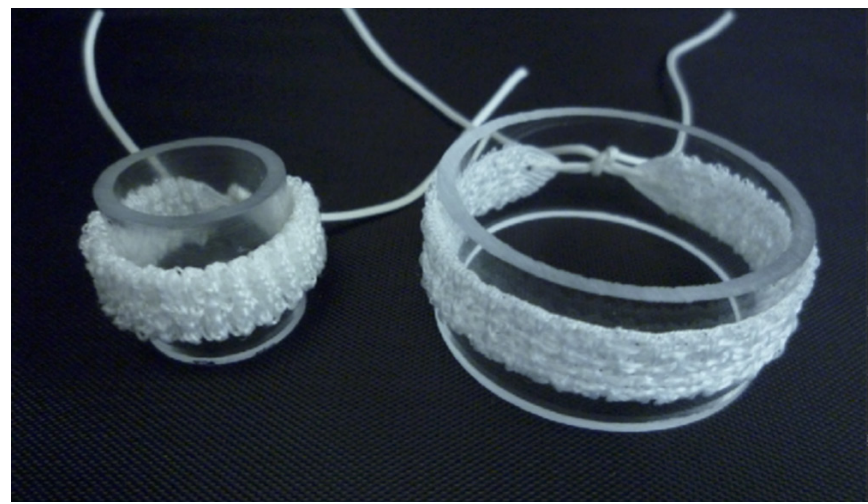

Fig. 2. The Leeds-Keio artificial ligament for Thiersch procedure. It consists of an expandable mesh tape (width, $1 \mathrm{~cm}$ ) and 2 threads attached to both ends. The contracted length of the mesh is $5 \mathrm{~cm}$ (left) and can be extended up to $10 \mathrm{~cm}$ (right).

\section{Statistical analysis}

Categorical variables are reported as frequencies and percentages, whereas continuous variables are reported as means and standard deviations. The cumulative recurrence-free rate was assessed using the Kaplan-Meier method. All statistical analyses were performed using EZR software ver. 1.11 (Saitama Medical Center, Jichi Medical University, Saitama, Japan).

\section{RESULTS}

From January 2009 to December 2020, rectal prolapse surgery was performed in 256 patients at our hospital. Of these, $106 \mathrm{pa}-$ tients (mean age, 81.2 years; range, 56-103 years) who underwent the ALTA-Thiersch procedure were included in the study. Patient characteristics are summarized in Table 1 . The mean length of rectal prolapse, operative time, and doses of ALTA per patient were $6.1 \pm 2.5 \mathrm{~cm}, 33.9 \pm 9.0$ minutes, and $24.6 \pm 8.9 \mathrm{~mL}$, respectively. The planned procedure was successful in 105 patients; however, in 1 patient, rectal perforation was observed during tunneling of the ischiorectal space, and the tape was inserted 1 month later. Rectal prolapse was cured shortly after ALTA-Thiersch in 105 patients (99.1\%); the prolapse persisted in 1 patient due to inadequate tightening of the encircling material. An additional ligament tape was inserted a week later, and the prolapse was successfully cured.

There were no treatment-related deaths. Postoperative complications were observed in 27 patients (25.5\%); these are summarized in Table 2. The rectal ulcer that occurred in 1 patient was associated with ALTA sclerotherapy, while the rest were considered to be Thiersch-related complications. Fecal impaction was the most common early complication (9.4\%), which occurred within 2 to 10 days (median, 4 days) after surgery. The fecal impactions were temporary and cured by digital disimpaction or enemas; therefore, no tape removal was required. 
Table 1. Characteristics of the patients

\begin{tabular}{|c|c|}
\hline Characteristic & Patient $(n=106)$ \\
\hline Age (yr) & $81.2 \pm 8.9$ \\
\hline Female sex & $93(87.7)$ \\
\hline Height (cm) & $148.8 \pm 8.3$ \\
\hline Weight (kg) & $48.9 \pm 11.2$ \\
\hline \multicolumn{2}{|l|}{ Vaginal delivery } \\
\hline 0 & $11(11.8)$ \\
\hline $1-2$ & $51(54.8)$ \\
\hline$\geq 3$ & 31 (33.3) \\
\hline \multicolumn{2}{|l|}{ Length of prolapse (cm) } \\
\hline$<5$ & $30(28.3)$ \\
\hline$\geq 5,<10$ & $63(59.4)$ \\
\hline$\geq 10$ & $13(12.3)$ \\
\hline \multicolumn{2}{|l|}{ Comorbid disease } \\
\hline Dementia & $21(19.8)$ \\
\hline Diabetes mellitus & 14 (13.2) \\
\hline Brain infarction & $9(8.5)$ \\
\hline Chronic heart failure & $9(8.5)$ \\
\hline Pulmonary emphysema & $8(7.5)$ \\
\hline Malignant tumor & $6(5.7)$ \\
\hline Ischemic heart disease & $5(4.7)$ \\
\hline Collagen disease & $4(3.8)$ \\
\hline Chronic renal failure & $4(3.8)$ \\
\hline Brain surgery & $4(3.8)$ \\
\hline Depression & $4(3.8)$ \\
\hline Liver cirrhosis & $3(2.8)$ \\
\hline
\end{tabular}

Values are presented as mean \pm standard deviation or number (\%).

The most common late complication was local infection (7.5\%), which occurred between 1 and 21 months (median, 3 months) after surgery. Tape exposure (2.8\%) occurred at 14-65 months (median, 48 months). Of the 12 cases in which the tape was infected or exposed, 1 case was cured with antibiotics, while the rest (10.4\%) required tape removal. Rectal prolapse recurred in 10 of the 11 patients who underwent tape removal.

The follow-up period for the 106 enrolled patients was 2 to 136 months. Fifty-five patients were available for follow-up after 12 months, and the follow-ups continued beyond 36 months for 17 patients. Recurrence was confirmed in 18 patients (17.0\%) at a mean follow-up duration of 22.1 months. Recurrent rectal prolapse was treated with reinsertion of a ligament tape in 5 patients, additional tape insertion in 3 patients, and mucosal sleeve resection in 3 patients; 7 patients who experienced recurrent rectal prolapse required no additional surgical treatment. Fig. 3 shows the Kaplan-Meier plots of recurrence-free probability for patients
Table 2. Complications

\begin{tabular}{lc}
\hline Type of complication & Case \\
\hline Intraoperative complication & $1(0.9)$ \\
Rectal injury & \\
Early ( $\leq 30$ days) complication & $10(9.4)$ \\
Fecal impaction & $1(0.9)$ \\
Local infection & $1(0.9)$ \\
Wound pain & $1(0.9)$ \\
Rectal ulcer & \\
Late (>30 days) complication & $2(1.9)$ \\
Fecal impaction & $8(7.5)$ \\
Local infection & $3(2.8)$ \\
Tape exposure & $1(0.9)$ \\
Tape knot loosening & $11(10.4)$ \\
Tape removal & $18(17.0)$ \\
Recurrence &
\end{tabular}

Values are presented as number (\%).

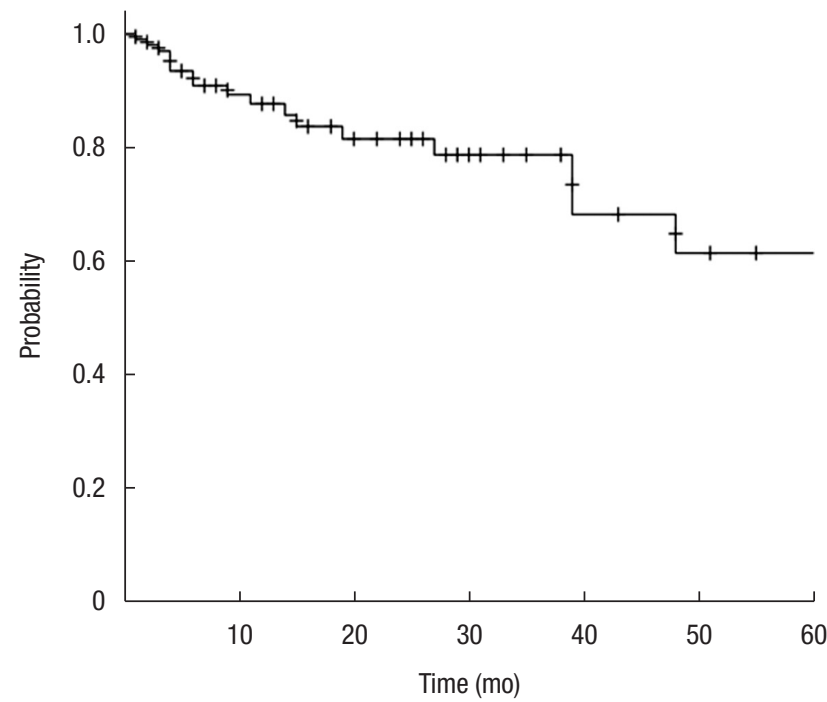

No. at risk

$\begin{array}{lllllll}106 & 55 & 37 & 24 & 12 & 8 & 5\end{array}$

Fig. 3. Probability of no recurrence with time for patients who underwent the treatment. Cumulative recurrence-free rates at 3 and 5 years postoperatively were $78.7 \%$ and $61.4 \%$, respectively.

after surgery. Cumulative recurrence-free rates (95\% confidence interval) at 3 and 5 years were $78.7 \%(65.5 \%-87.3 \%)$ and $61.4 \%$ $(39.3 \%-77.5 \%)$, respectively.

\section{DISCUSSION}

This study demonstrated that the efficacy of ALTA-Thiersch for 
rectal prolapse was comparable to that of other perineal procedures. Use of the artificial ligament tape for the Thiersch procedure eliminated postoperative defecation difficulties and consequent tape removal. However, the incidence of local infections did not decrease, and further improvement of their antibacterial properties of the ligament tape may be necessary.

Abdominal operations for rectal prolapse, including laparoscopic ventral rectopexy, are generally considered to have a lower recurrence rate than that of perineal procedures [1]. However, a recent Cochrane review analyzed 15 randomized trials involving 1,007 patients reporting no significant difference in recurrence rates between the 2 approaches [2]. There are 2 commonly performed perineal approaches: Delorme's procedure (mucosal sleeve resection) is widely used in the United Kingdom, while Altemeier's procedure (perineal rectosigmoidectomy) is popular in North America [2]. The recurrence rates of the 2 procedures have been reported to be $8 \%-53 \%$ and $0 \%-35 \%$, respectively [ 1 , 16]. In our study, the 3-year recurrence rate of the ALTA-Thiersch procedure was $21.3 \%$; therefore, we consider it feasible in terms of curability.

Perineal procedures may help prevent the need for laparotomy and have a lower operative risk; however, there is no definite evidence to support this. The mortality rates for the Delorme's and Altemeier's procedures ranged from $0 \%-5 \%$ and $0 \%-3 \%$, and morbidity ranged from $0 \%-77 \%$, and $0 \%-38 \%$, respectively [1, 16]. The potential complications of these procedures include hemorrhage in the suture line and pelvic sepsis due to anastomotic leakage. On the other hand, ALTA-Thiersch does not require resection or suturing of the rectum; thus, there is no risk of postoperative bleeding and suture failure. In this study, the complication rate after ALTA-Thiersch was 25.5\%, but none of the complications were serious. Thus, we believe that ALTA-Thiersch, which has less potential surgical risk, is the most promising procedure for frail, elderly, and high-risk patients.

The Leeds-Keio ligament was developed through a collaborative project between the University of Leeds in the United Kingdom and Keio University in Japan [14]. Currently, silicone or polypropylene products are often used as encircling materials in rectal prolapse surgery because they are tough, inert, and elastic [2]. Sainio et al. [17] reported that fecal impaction occurred in 17.6\% of patients (3 of 17) after anal encircling using a polypropylene mesh. Chan et al. [18] also reported that fecal impaction occurred in $79.2 \%$ of patients (19 of 24 ) who underwent the Thiersch procedure using a silastic tube or polypropylene mesh. The LeedsKeio ligament for Thiersch is pliable, elastic, and can be expanded to allow normal defecation. Therefore, persistent fecal impaction after ALTA-Thiersch is rare, and in our experience, no patients required tape removal due to obstructive defecation.

However, 11 cases (10.4\%) in this study required tape removal due to local infection or tape exposure. In previous studies involving the Thiersch procedure, the reported removal rates for the prosthesis ranged from $0 \%$ to $39.4 \%$ (mean, $14.5 \%$ ), with the most common causes being local infections [10-13, 17-20]. Local infection rates after the Thiersch procedure were reported to be $8.3 \%$ to $26.7 \%$ for silicone prostheses $[10,12,13,20], 0 \%$ to $17.6 \%$ for polypropylene prostheses $[17,18], 20.0 \%$ for polyester grafts [11], and 4.0\% for biological meshes [19]. The Leeds-Keio ligament made of polyester mesh had a low infection rate of 7.5\% (8 of 106) among current prostheses, but it required almost complete removal because antibiotics were ineffective against the infection. In our opinion, local infections and tape exposure are less likely to occur if the ligament tape is inserted neatly and deeply, and they can be mitigated by an experienced surgeon. In the future, better results may be obtained by coating or impregnating the ligaments with antibiotics to enhance their antibacterial properties.

The Thiersch procedure does not cure the redundant rectum; it merely confines it mechanically above the anus. Therefore, some combined treatments involving anal encirclement and with other procedures have been reported. Ammar et al. [21] described a procedure combining anal encirclement with sclerotherapy using $5 \%$ ethanolamine oleate and reported that rectal prolapse recurred in 6 of 20 patients (30\%). Eftaiha et al. [19] combined perineal proctectomy with the Thiersch procedure using a biological mesh, and recurrent prolapse was observed in 2 of 25 patients (8\%). Iida et al. [22] performed rectal mucosal plication in conjunction with the Thiersch procedure in 166 cases of rectal prolapse and reported a recurrence rate of $8.4 \%$. Although the recurrence rate after ALTA-Thiersch was $17.0 \%$ in our study, we believe that ALTA-Thiersch has the lowest potential risk of postoperative complications among these combined procedures.

The limitations of this study include its retrospective, single-institution, and observational design, with no control group included. Another limitation is that functional abnormalities, such as constipation, fecal incontinence, and quality of life were not evaluated before and after treatment. Further, since the office visits after 3 years were optional, the number of follow-ups steadily decreased. Therefore, the recurrence rate may have been overestimated or underestimated. Thus, the results need to be validated through randomized controlled trials. Comparative studies with other perineal procedures are also required.

In conclusion, the ALTA-Thiersch procedure is simple and safe for treating rectal prolapse and has reasonable outcomes. The use of the Leeds-Keio ligament for anal encircling helps prevent the disadvantages of the Thiersch operation. Therefore, this technique could be an important surgical option for frail and highrisk patients. If the antibacterial property of the ligament is further improved, the Thiersch procedure may become one of the main surgical treatment modalities for rectal prolapse.

\section{CONFLICT OF INTEREST}

No potential conflict of interest relevant to this article was reported. 


\section{REFERENCES}

1. Bordeianou L, Paquette I, Johnson E, Holubar SD, Gaertner W, Feingold DL, et al. Clinical practice guidelines for the treatment of rectal prolapse. Dis Colon Rectum 2017;60:1121-31.

2. Tou S, Brown SR, Nelson RL. Surgery for complete (full-thickness) rectal prolapse in adults. Cochrane Database Syst Rev 2015;2015: CD001758.

3. Abe T, Hachiro Y, Kunimoto M. Combined aluminum potassium sulfate and tannic acid sclerosing therapy and anal encirclement using an elastic artificial ligament for rectal prolapse. Dis Colon Rectum 2014;57:653-7.

4. Shi Z, Zhou J, He X. On treatment of third-degree internal hemorrhoids with "Xiaozhiling" injection. J Trad Chin Med 1981; 1:115-20.

5. Takano M, Iwadare J, Ohba H, Takamura H, Masuda Y, Matsuo K, et al. Sclerosing therapy of internal hemorrhoids with a novel sclerosing agent: comparison with ligation and excision. Int J Colorectal Dis 2006;21:44-51.

6. Hachiro Y, Kunimoto M, Abe T, Kitada M, Ebisawa Y. Aluminum potassium sulfate and tannic acid (ALTA) injection as the mainstay of treatment for internal hemorrhoids. Surg Today 2011; 41:806-9.

7. Hachiro Y, Kunimoto M, Abe T, Kitada M, Ebisawa Y. Aluminum potassium sulfate and tannic acid injection in the treatment of total rectal prolapse: early outcomes. Dis Colon Rectum 2007;50: 1996-2000.

8. Abe T, Kunimoto M, Hachiro Y, Ebisawa Y. Injection sclerotherapy using aluminum potassium sulfate and tannic acid in the treatment of symptomatic rectocele: a prospective case series. Int J Surg 2016;30:94-8.

9. Thiersch C. Carl Thiersch 1822-1895: concerning prolapse of the rectum with special emphasis on the operation by Thiersch. Dis Colon Rectum 1988;31:154-5.

10. Horn HR, Schoetz DJ Jr, Coller JA, Veidenheimer MC. Sphincter repair with a Silastic sling for anal incontinence and rectal procidentia. Dis Colon Rectum 1985;28:868-72.
11. Poole GV Jr, Pennell TC, Myers RT, Hightower F. Modified Thiersch operation for rectal prolapse: technique and results. Am Surg 1985;51:226-9.

12. Larach SW, Vazquez B. Modified Thiersch procedure with silastic mesh implant: a simple solution for fecal incontinence and severe prolapse. South Med J 1986;79:307-9.

13. Devesa JM, Hervás PL, Vicente R, Rey A, Die J, Moreno I, et al. Anal encirclement with a simple prosthetic sling for faecal incontinence. Tech Coloproctol 2011;15:17-22.

14. Jones AP, Sidhom S, Sefton G. Long-term clinical review (10-20 years) after reconstruction of the anterior cruciate ligament using the Leeds-Keio synthetic ligament. J Long Term Eff Med Implants 2007;17:59-69.

15. Iwadare J, Takahashi T, Yamana T. [Thiersch procedure using elastic polyester-mesh]. J Jpn Soc Colorectal Anal Dis 2005;58: 452-3. In Japanese.

16. Tsunoda A. Surgical treatment of rectal prolapse in the laparoscopic era; a review of the literature. J Anus Rectum Colon 2020; 4:89-99.

17. Sainio AP, Halme LE, Husa AI. Anal encirclement with polypropylene mesh for rectal prolapse and incontinence. Dis Colon Rectum 1991;34:905-8.

18. Chan RH, Lin BW, Lin SC, Lee JC. Thiersch procedure for rectal prolapse: experiences from a single institution. Int Surg 2017;102: $10-4$.

19. Eftaiha SM, Calata JF, Sugrue JJ, Marecik SJ, Prasad LM, Mellgren A, et al. Bio-Thiersch as an adjunct to perineal proctectomy reduces rates of recurrent rectal prolapse. Dis Colon Rectum 2017; 60:187-93.

20. Lim CH, Kang WH, Lee YC, Ko YT, Yoo BE, Yang HK. Standardized method of the Thiersch operation for the treatment of fecal incontinence. World J Surg 2020;44:3141-8.

21. Ammar SA, Kottb MB. A novel percutaneous technique for treating complete rectal prolapse in adults. Surg Innov 2015;22:240-4.

22. Iida Y, Honda K, Saitou H, Munemoto Y, Tanaka H. Modified Gant-Miwa-Thiersch procedure (mucosal plication with anal encircling) for rectal prolapse. Colorectal Dis 2019;21:588-94. 